Lung (1992) 170:51-62

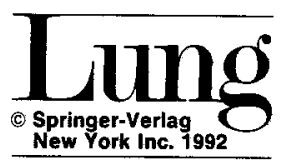

\title{
Pulmonary Responses of Asthmatic and Normal Subjects to Different Temperature and Humidity Conditions in an Environmental Chamber
}

\author{
William L. Eschenbacher, ${ }^{1}$ Thomas B. Moore, ${ }^{3}$ Thomas J. Lorenzen, ${ }^{3}$ \\ John G. Weg, ${ }^{2}$ and Kenneth B. Gross ${ }^{3}$ \\ ${ }^{1}$ Pulmonary Function Laboratory F988, The Methodist Hospital, 6565 Fannin, Houston, TX \\ 77030, USA, ${ }^{2}$ Pulmonary and Critical Care Medicine, University of Michigan Medical Center, \\ Ann Arbor, MI, USA, and ${ }^{3}$ Biomedical Science and Mathematics Departments, General \\ Motors Research Laboratories, Warren, MI, USA
}

\begin{abstract}
Determining the possible adverse health effects of air pollutants can be complicated by differences in the environmental conditions of temperature and humidity. To evaluate the potentially confounding effects of differences in temperature and humidity, we exposed 8 normal male subjects and 8 male subjects with asthma to the extremes in temperature and humidity that could be maintained in an environmental chamber. We performed serial pulmonary function tests for these subjects before and during $6 \mathrm{hr}$ exposure periods on 5 separate occasions: cold, dry $\left(10^{\circ} \mathrm{C}, 10 \%\right.$ relative humidity); cold, humid $\left(10^{\circ} \mathrm{C}, 50 \%\right.$ relative humidity); normal ambient $\left(22^{\circ} \mathrm{C}, 40 \%\right.$ relative humidity); hot, dry $\left(37^{\circ} \mathrm{C}, 15 \%\right.$ relative humidity); and hot, humid $\left(37^{\circ} \mathrm{C}, 60 \%\right.$ relative humidity). The exposure period included a 12 min exercise on a cycle ergometer. We found no significant change in spirometry, airways resistance, or diffusing capacity for either group of subjects at rest alone over the $6 \mathrm{hr}$ period of exposure for any exposure condition. However, there were changes in spirometry and airways resistance as a result of the $12 \mathrm{~min}$ period of exercise. The subjects with asthma had significant decreases in forced expiratory volume in $1 \mathrm{sec}\left(\mathrm{FEV}_{1}\right)(20-21 \%)$ and increases in specific airways resistance when exercising in conditions of cold and dry, cold and humid, and hot and dry. The normal subjects had an average increase in $F E V_{1}$ of approximately $6 \%$ when exercising in the hot and humid conditions. We found significant correlations for the changes in $\mathrm{FEV}_{1}$ with the water content of the exposure conditions for both groups of subjects. We also found that the work performance (expressed as the external work performed divided by the oxygen consumed) was decreased for the subjects in both groups at
\end{abstract}


the conditions of the higher temperature $\left(37^{\circ} \mathrm{C}\right)$ compared with the lower temperature $\left(10^{\circ} \mathrm{C}\right)$. These results confirm that controlling for the conditions of temperature and humidity is essential in chamber studies, field studies, or epidemiologic evaluations determining the adverse effect of an air pollutant.

Key words: Air pollution-Heat stress-Exercise testing-Bronchoconstriction.

\section{Introduction}

The impact of various environmental pollutants on the pulmonary function of normal human subjects and subsets of sensitive human subjects has been an important area of research in recent years. There is concern that the inhalation of pollutants such as ozone, nitrogen dioxide, sulfur dioxide, sulfuric acid aerosols, and others may result in both acute and long-term adverse effects on the lung. It is obviously important in the design of experimental protocols to study the effects of these pollutants so that potentially confounding variables or factors can be eliminated. Factors that, by themselves, have been shown to alter the lung function of sensitive persons, such as subjects with asthma, are differences in the temperature and humidity of the environment $[1-3,8]$. It has been well established from these previous studies that asthmatic subjects may experience bronchoconstriction when they exercise or hyperventilate in environmental conditions other than body-temperature $\left(37^{\circ} \mathrm{C}\right)$, completely saturated (100\% relative humidity) air. In controlled chamber studies examining responses to pollutants, temperature and humidity conditions are frequently set arbitrarily. In field and epidemiologic studies, environmental conditions often vary with the environmental pollutant under consideration. For example, higher ozone concentrations are usually associated with periods of greater solar radiation and higher ambient temperatures [5]. However, the possible contribution of temperature and humidity changes to the pulmonary response attributed to the pollutant is often unknown. To evaluate the effect that differences in temperature and humidity alone would have on pulmonary function in both normal subjects and sensitive subjects such as persons with asthma, we designed and carried out a controlled study using the extremes in temperature and humidity that could be generated in an environmental chamber. We studied both normal subjects and subjects with asthma and exposed them to the conditions of the chamber for a total of $6 \mathrm{hr}$. We measured lung function (spirometry, airways resistance, and diffusing capacity) before exposure, at rest during exposure, and after exercise during exposure. The results from this study can be used to evaluate the possible confounding influences of temperature and humidity in epidemiologic, field, and controlled chamber studies.

\section{Methods}

\section{Subject Selection}

Approval for this study was obtained from the Human Research Committees at both the University of Michigan Medical Center and the General Motors Research Laboratories. Eight normal male 
Table 1. Characteristics of study subjects

\begin{tabular}{|c|c|c|c|c|c|c|c|}
\hline Subject & Sex & $\begin{array}{l}\text { Age } \\
(\mathrm{yr})\end{array}$ & $\begin{array}{l}\text { Height } \\
\text { (cm) }\end{array}$ & $\begin{array}{l}\text { Weight } \\
(\mathrm{kg})\end{array}$ & $\begin{array}{l}\mathrm{FEV}_{1} \\
\text { (L) }\end{array}$ & $\begin{array}{l}\text { FVC } \\
\text { (L) }\end{array}$ & $\begin{array}{l}\text { Medication } \\
\text { used }\end{array}$ \\
\hline \multicolumn{8}{|c|}{ Asthmatic subjects } \\
\hline 1 & $\mathbf{M}$ & 21 & 182.9 & 72.3 & 3.95 & 4.87 & IB \\
\hline 2 & $\mathbf{M}$ & 22 & 180.3 & 72.7 & 4.60 & 5.33 & IB \\
\hline 3 & M & 23 & 165.1 & 61.4 & 3.33 & 4.20 & None \\
\hline 4 & $\mathrm{M}$ & 24 & 188.0 & 77.3 & 3.85 & 5.46 & IB,IC \\
\hline 5 & M & 36 & 175.3 & 100.3 & 2.80 & 4.86 & IB,IC,T \\
\hline 6 & $\mathrm{M}$ & 23 & 170.2 & 72.7 & 1.60 & 4.68 & $\mathrm{IB}, \mathrm{T}$ \\
\hline 7 & $\mathbf{M}$ & 21 & 182.9 & 66.8 & 3.16 & 5.65 & IB, $\mathrm{T}$ \\
\hline 8 & $\mathbf{M}$ & 20 & 180.3 & 75.0 & 2.29 & 4.15 & IB, $T$ \\
\hline \multicolumn{8}{|c|}{ Normal subjects } \\
\hline 1 & $\mathbf{M}$ & 27 & 182.9 & 95.5 & 3.79 & 4.91 & \\
\hline 2 & M & 29 & 182.9 & 77.3 & 3.57 & 5.20 & \\
\hline 3 & $\mathbf{M}$ & 19 & 175.3 & 77.3 & 3.97 & 4.66 & \\
\hline 4 & M & 36 & 182.9 & 72.7 & 4.22 & 4.59 & \\
\hline 5 & M & 25 & 180.3 & 102.3 & 3.67 & 4.55 & \\
\hline 6 & M & 29 & 165.1 & 65.5 & 3.98 & 4.62 & \\
\hline 7 & $\mathbf{M}$ & 28 & 193.0 & 86.4 & 4.54 & 5.15 & \\
\hline 8 & $\mathbf{M}$ & 26 & 180.3 & 76.4 & 5.68 & 6.92 & \\
\hline
\end{tabular}

IB, inhaled bronchodilator; IC, inhaled cromolyn; $T$, theophylline

subjects and 8 male subjects with asthma participated in the protocol. All subjects were nonsmokers and signed informed consent forms before entering the study. Each subject underwent an initial evaluation at the University of Michigan that included a history and physical examination, baseline pulmonary function tests, and an exercise test to determine maximal oxygen consumption (see below). Each subject with asthma had a history of reversible chest tightness and wheezing, had previously had the diagnosis of asthma made by a physician, and demonstrated at least a $15 \%$ increase in baseline $\mathrm{FEV}_{1}$ after the 1-time use of a bronchodilator given as part of the initial screening pulmonary function tests. Characteristics of the study subjects are shown in Table 1.

\section{Exposure Chamber}

All exposures were conducted in a $4 \times 4 \times 3 \mathrm{~m}$ stainless steel environmental chamber at the General Motors Research Laboratories, Warren (MI) and described previously [10]. The air entering the chamber passed through a purification system consisting of Purafil chemisorbent, HEPA filters, Hopcalite catalyst, and treated charcoal to remove particles, $\mathrm{NO}_{2}, \mathrm{CO}, \mathrm{NH}_{3}$, and $\mathrm{SO}_{2}$. Temperature and relative humidity conditions were set for each exposure according to the protocol, and the conditions were closely monitored and controlled by a computer-assisted system. The following five conditions of temperature and humidity were examined: $10^{\circ} \mathrm{C}$ and $10 \%$ relative humidity, water content of $0.9 \mathrm{mg} / \mathrm{L}$ (cold, dry); $10^{\circ} \mathrm{C}$ and $50 \%$ relative humidity, water content of $4.7 \mathrm{mg} / \mathrm{L}$ (cold, humid); $22^{\circ} \mathrm{C}$ and $40 \%$ relative humidity, water content of $7.8 \mathrm{mg} / \mathrm{L}$ (normal ambient); $37^{\circ} \mathrm{C}$ and $15 \%$ relative humidity, water content of $6.6 \mathrm{mg} / \mathrm{L}$ (hot, dry); $37^{\circ} \mathrm{C}$ and $60 \%$ relative humidity, water content of $26.4 \mathrm{mg} / \mathrm{L}$ (hot, humid). These conditions represent the extremes that could be maintained in this environmental chamber. 


\section{Pulmonary Function Tests and Exercise Tests}

The following pulmonary function tests were performed as part of the initial characterization and during the exposure protocol: spirometry $\left(\mathrm{FEV}_{1}\right.$, forced vital capacity $[\mathrm{FVC}], \mathrm{FEV}_{1} / \mathrm{FVC}$, forced expiratory flow $[\mathrm{FEF}]_{\max }, \mathrm{FEF}_{25}, \mathrm{FEF}_{50}$, and $\mathrm{FEF}_{75}$ ) and diffusing capacity using pulmonary function analyzers (Microloop and System 1070, Medical Graphics Corp., St. Paul, MN), and airways resistance and thoracic gas volumes (Raw and TGV) using body plethysmography (System 1085, Medical Graphics Corp., St. Paul, MN). In the subjects with asthma spirometry was repeated after the 1-time use of the beta-adrenergic bronchodilator isoetharine. All subjects with asthma in this protocol had greater than a $15 \%$ increase in the $\mathrm{FEV}_{1}$ after use of the bronchodilator. Each subject also performed a progressive exhaustive exercise test as part of the initial characterization and then exercised for $12 \mathrm{~min}$ during each $6 \mathrm{hr}$ exposure period in the environmental chamber. The initial exercise test was performed on a treadmill with an incremental workload protocol provided by the manufacturer of the treadmill (Marquette Electronics series 1825, Marquette WI). Analysis of exhaled gases and minute ventilation was performed using a computer-based exercise system (System 2001, Medical Graphics Corp., St. Paul, MN). From the results of this initial exercise test, the maximal oxygen consumption was determined for each subject. This value was then used during the exercise portion of each exposure period as described below.

\section{Protocol}

Each subject came to the General Motors Research Laboratories on 5 separate occasions. On each occasion, the subject followed the same testing protocol. The only difference among the separate visits was the temperature and humidity of the environmental chamber. Each subject was exposed in a randomized fashion to the 5 different conditions of temperature and relative humidity listed above. Asthmatic subjects discontinued use of methylxanthine medications for $36 \mathrm{hr}$ and betaagonist inhalers for $12 \mathrm{hr}$ before the beginning of each exposure period. At the beginning of each study day, each subject had a baseline measurement of airways resistance and thoracic gas volume for the determination of specific airways resistance (SRaw). After entering the chamber, the subject had the remaining baseline pulmonary function tests performed: spirometry and diffusing capacity. The subject sat in the chamber for $2 \mathrm{hr}$ followed by repeat measurement of SRaw and spirometry. The subject rested for 2 more hours in the chamber and then performed $12 \mathrm{~min}$ of exercise on a cycle ergometer (type KEM-2, Mijnhardt, Odijk, The Netherlands) located within the chamber. After 2 min of gas collection at rest (System 2001, Medical Graphics Corp., St. Paul, MN), the subject cycled for $2 \mathrm{~min}$ at a workload to achieve $50 \%$ of the target maximal workload (that necessary to achieve $75 \%$ of the maximal oxygen consumption as determined by the progressive exercise test done as part of the initial characterization). The subject then exercised for $10 \mathrm{~min}$ at the target maximal workload. After exercise, the subject rested for $10 \mathrm{~min}$ and had measurements of SRaw and spirometry repeated. The subject then sat in the chamber for another $1 \frac{1}{2} \mathrm{hr}$ and had all pulmonary function tests performed at $6 \mathrm{hr}$ after first entering the chamber (SRaw, spirometry, and diffusing capacity). This completed the testing protocol for that day.

\section{Data Analysis}

All data are expressed as mean values \pm the standard error of the mean (SEM). Statistical comparisons were made using analysis of variance supplemented with Duncan's multiple-range test to determine significant differences between time points and exposure conditions. A significance level of $p=0.05$ was applied in all statistical analyses.

\section{Results}

\section{Pulmonary Function Tests}

$F E V_{1}$. The mean values for the $F E V_{1}$ for all 5 exposure conditions at baseline, after $2 \mathrm{hr}$ of exposure, at $10 \mathrm{~min}$ after the period of exercise at $4 \mathrm{hr}$, and after 
Table 2. Measurements of $\mathrm{FEV}_{1}$ for asthmatic and normal subjects during different exposure conditions (mean $\pm \mathrm{SEM}$ )

\begin{tabular}{|c|c|c|c|c|}
\hline \multirow{2}{*}{$\begin{array}{l}\text { Exposure } \\
\text { condition }^{\mathrm{a}}\end{array}$} & \multicolumn{4}{|c|}{ Time of measurement } \\
\hline & Baseline & $2 \mathrm{hr}$ & $\begin{array}{l}10 \text { min after } \\
\text { exercise at } \\
4 \mathrm{hr}\end{array}$ & $6 \mathrm{hr}$ \\
\hline \multicolumn{5}{|l|}{ Asthmatic subjects } \\
\hline Cold, dry & $3.50 \pm 0.21$ & $3.46 \pm 0.28$ & $2.87 \pm 0.34^{\mathrm{b}}$ & $3.64 \pm 0.21$ \\
\hline Cold, humid & $3.70 \pm 0.19$ & $3.57 \pm 0.20$ & $2.97 \pm 0.29^{\mathrm{b}}$ & $3.49 \pm 0.36$ \\
\hline Hot, dry & $3.67 \pm 0.26$ & $3.76 \pm 0.25$ & $3.09 \pm 0.04^{b}$ & $3.74 \pm 0.28$ \\
\hline Normal ambient & $3.76 \pm 0.28$ & $3.72 \pm 0.28$ & $3.49 \pm 0.37$ & $3.88 \pm 0.30$ \\
\hline Hot, humid & $3.69 \pm 0.21$ & $3.66 \pm 0.23$ & $3.60 \pm 0.26$ & $3.72 \pm 0.27$ \\
\hline \multicolumn{5}{|l|}{ Normal subjects } \\
\hline Cold, dry & $4.23 \pm 0.26$ & $4.20 \pm 0.25$ & $4.30 \pm 0.25$ & $4.17 \pm 0.24$ \\
\hline Cold, humid & $4.23 \pm 0.25$ & $4.29 \pm 0.26$ & $4.32 \pm 0.27$ & $4.22 \pm 0.26$ \\
\hline Hot, dry & $4.20 \pm 0.25$ & $4.27 \pm 0.25$ & $4.30 \pm 0.27$ & $4.29 \pm 0.24$ \\
\hline Normal ambient & $4.27 \pm 0.27$ & $4.27 \pm 0.25$ & $4.38 \pm 0.26$ & $4.22 \pm 0.27$ \\
\hline Hot, humid & $4.26 \pm 0.26$ & $4.39 \pm 0.27$ & $4.52 \pm 0.27^{b}$ & $4.41 \pm 0.26$ \\
\hline
\end{tabular}

a Cold, dry $=10^{\circ} \mathrm{C}, 10 \%$ relative humidity; cold, humid $=10^{\circ} \mathrm{C}, 50 \%$ relative humidity; hot, dry $=37^{\circ} \mathrm{C}, 15 \%$ relative humidity; normal ambient $=37^{\circ} \mathrm{C}, 40 \%$ relative humidity; hot, humid $=$ $37^{\circ} \mathrm{C}, 60 \%$ relative humidity

b The percentage changes from baseline for these values are significantly different $(p<0.05$ ) than the percentage changes at other conditions and at the other times of measurements for the same conditions

$6 \mathrm{hr}$ of exposure for the 8 normal subjects and the 8 subjects with asthma are shown in Table 2. The percentage changes in $\mathrm{FEV}_{1}$ compared to the baseline values for the 5 different exposure conditions for the subjects with asthma and the normal subjects are shown in Figs. 1 and 2. There were no significant changes in $\mathrm{FEV}_{1}$ after $2 \mathrm{hr}$ or after $6 \mathrm{hr}$ of exposure for any exposure condition for either the normal subjects or the subjects with asthma. However, after the exercise at $4 \mathrm{hr}$ of exposure, the decrease in $\mathrm{FEV}_{1}$ for the subjects with asthma was significantly greater for the conditions of cold and dry $(-20.7 \pm 6.6 \%)$, cold and humid $(-20.3 \pm 4.5 \%)$, and hot and dry $(-20.4 \pm 7.3 \%)$ than at the other times of the protocol and for the other exposure conditions $(p<0.05)$. The increase in the $\mathrm{FEV}_{1}$ for the normal subjects after the exercise period for the hot and humid condition $(+6.3 \pm 0.8 \%)$ was also significantly greater than for the changes in $\mathrm{FEV}_{1}$ for these normal subjects at the other times of the protocol and for the other exposure conditions $(\mathrm{p}<0.05)$. When the changes in $\mathrm{FEV}_{1}$ after the exercise period at $4 \mathrm{hr}$ of exposure for all exposure conditions for the normal subjects and the subjects with asthma are regressed against the water content in $\mathrm{mg} / \mathrm{L}$ for the exposure condition, the resulting relationships are shown in Fig. 3. There are statistically significant correlations for the linear regressions of these relationships for both the normal subjects $(\mathrm{r}=0.995, \mathrm{p}=$ 0.0004) and the subjects with asthma $(\mathrm{r}=0.897, \mathrm{p}=0.0392)$.

$S R a w, F E V_{1} / F V C$. The mean values for $S R a w$ and $F E V_{1} / F V C$ for all 5 exposure 
W. L. Eschenbacher et al.

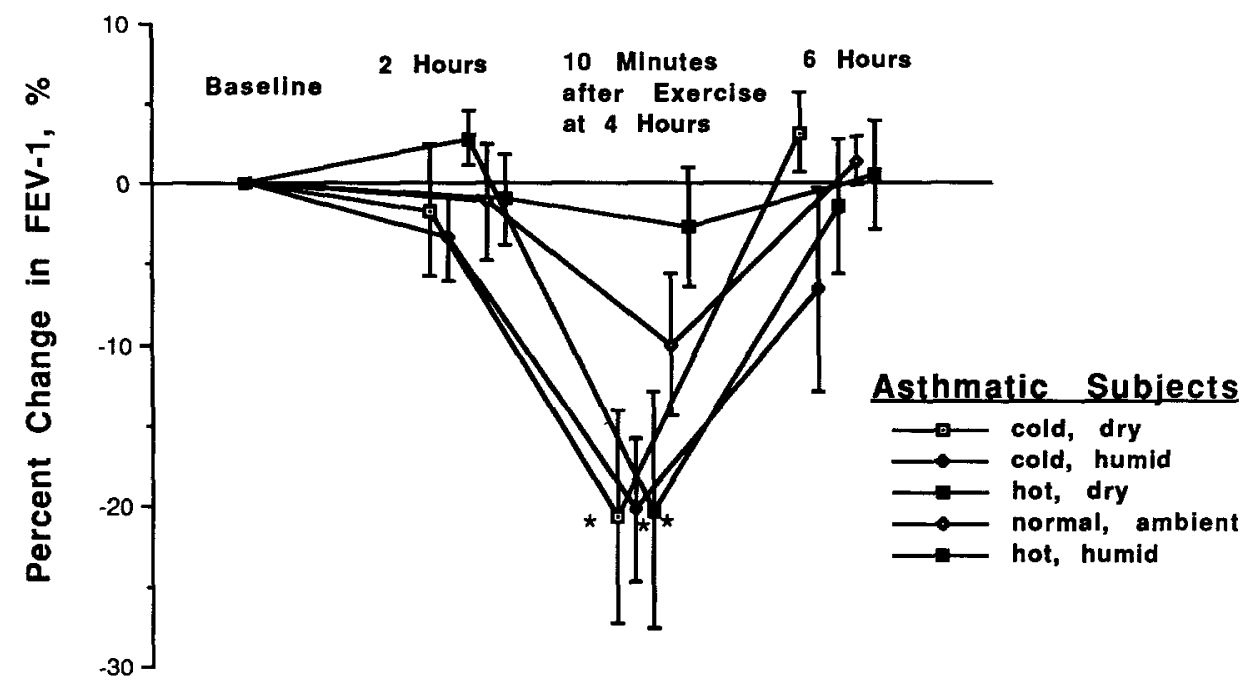

Fig. 1. Percentage change in $\mathrm{FEV}_{1}$ compared with baseline values for the 8 subjects with asthma during the $6 \mathrm{hr}$ exposure periods on the 5 separate exposure days. Values shown are mean \pm SEM. * Changes that are significantly different compared with the other changes $(p<0.05)$. See text for temperature and humidity conditions of each exposure day.

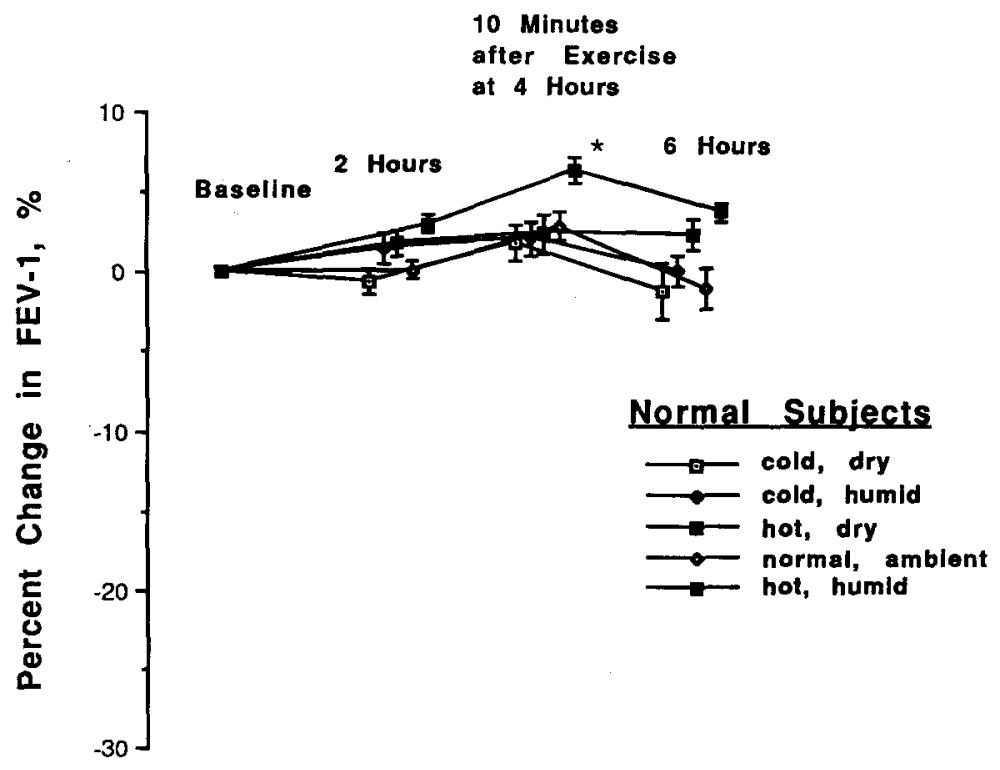

Fig. 2. Percentage change in $F E V_{1}$ compared with baseline values for the 8 normal subjects during the $6 \mathrm{hr}$ exposure periods on the five separate exposure days. Values shown are mean \pm SEM. * Changes that are significantly different compared with the other changes $(p<0.05)$. See text for temperature and humidity conditions of each exposure day. 


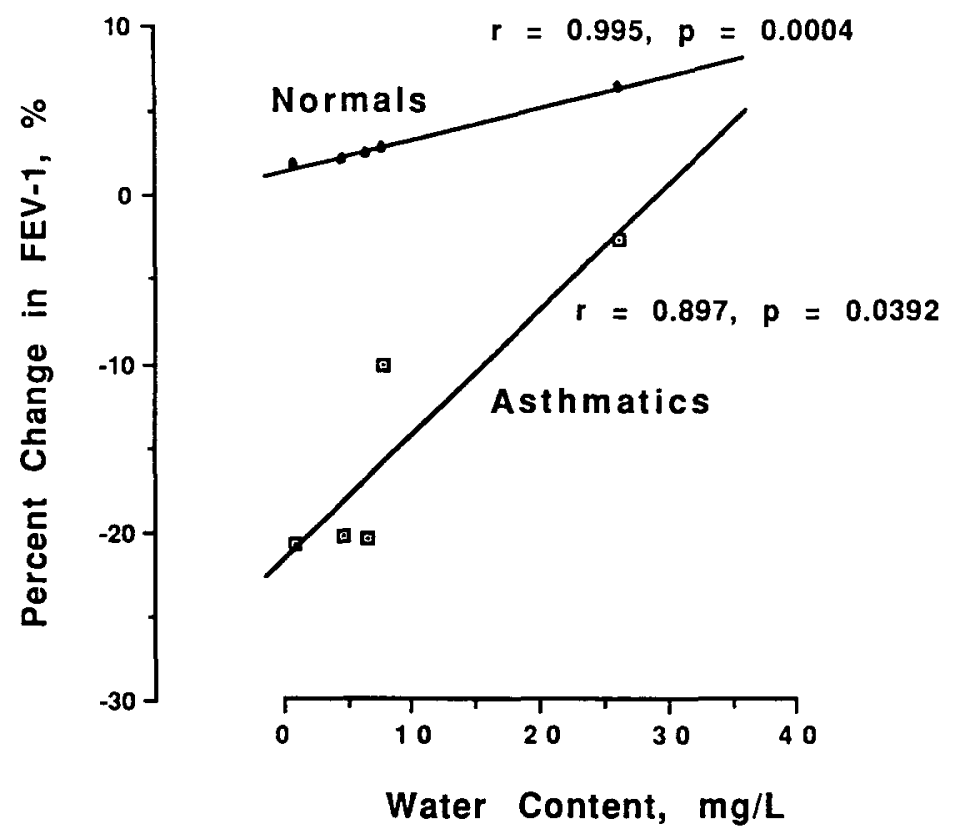

Fig. 3. Relationships between percentage change in $F E V_{L}$ and the water content of the exposure conditions of the 5 separate exposure days for the groups of subjects: normal and asthmatic subjects.

conditions for the normal subjects and the subjects with asthma are shown in Tables 3 and 4, respectively. The changes in these values parallel the changes in $\mathrm{FEV}_{1}$ described above. The subjects with asthma had the following percentage increases in SRaw after the exercise period at $4 \mathrm{hr}:+158.7 \pm 63.2 \%$ (hot and dry); $+90.6 \pm 21.4 \%$ (cold and dry); and $+72.7 \pm 17.0 \%$ (cold and humid). These percentage increases in SRaw were all significantly greater than the changes in SRaw for the other time points without exercise $(\mathrm{p}<0.05)$.

Diffusing Capacity. There were no differences in the diffusing capacities for either the normal subjects or the subjects with asthma when the baseline values are compared to the values after the exposure for any of the exposure conditions. The mean values for the subjects with asthma are $38.4 \pm 0.8 \mathrm{ml} / \mathrm{min} / \mathrm{mmHg}$ at baseline and $38.5 \pm 0.7 \mathrm{ml} / \mathrm{min} / \mathrm{mmHg}$ after $6 \mathrm{hr}$ of exposure. The mean values for the normal subjects are $41.7 \pm 0.8 \mathrm{ml} / \mathrm{min} / \mathrm{mmHg}$ at baseline and $42.2 \pm 0.8$ $\mathrm{ml} / \mathrm{min} / \mathrm{mmHg}$ after $6 \mathrm{hr}$ of exposure.

\section{Work Performance}

To be consistent for the exercise periods of the different exposure conditions, we set the target workload for each subject based on the results of the initial exercise study performed on the characterization day, but then adjusted the workload for the subsequent exposures so that the minute ventilations were the 
Table 3. Measurements of specific airways resistance (SRaw) for asthmatic and normal subjects during different exposure conditions (mean \pm SEM)

\begin{tabular}{lrrrr}
\hline $\begin{array}{l}\text { Exposure } \\
\text { condition }^{\mathrm{a}}\end{array}$ & \multicolumn{4}{c}{ Time of measurement } \\
\cline { 2 - 5 } & Baseline & $2 \mathrm{hr}$ & $\begin{array}{l}\text { 10 min after } \\
\text { exercise at } \\
\text { 4 hr }\end{array}$ & $6 \mathrm{hr}$ \\
& & & & \\
\hline Asthmatic subjects & & & & \\
Cold, dry & $10.7 \pm 0.9$ & $11.4 \pm 1.6$ & $20.1 \pm 2.2^{\mathrm{b}}$ & $9.8 \pm 0.6$ \\
Cold, humid & $9.8 \pm 0.6$ & $9.6 \pm 1.1$ & $16.4 \pm 2.9^{\mathrm{b}}$ & $11.9 \pm 2.9$ \\
Hot, dry & $9.4 \pm 0.6$ & $8.9 \pm 1.2$ & $22.5 \pm 4.3^{\mathrm{b}}$ & $9.5 \pm 0.8$ \\
Normal ambient & $8.7 \pm 0.7$ & $9.5 \pm 1.5$ & $13.2 \pm 1.3$ & $8.4 \pm 0.9$ \\
Hot, humid & $8.8 \pm 0.2$ & $9.2 \pm 1.0$ & $10.5 \pm 1.6$ & $9.7 \pm 1.1$ \\
Normal subjects & & & & \\
Cold, dry & $6.7 \pm 0.6$ & $5.9 \pm 0.5$ & $6.8 \pm 0.3$ & $5.8 \pm 0.4$ \\
Cold, humid & $6.2 \pm 0.4$ & $6.2 \pm 0.4$ & $7.6 \pm 0.2$ & $6.2 \pm 0.3$ \\
Hot, dry & $6.4 \pm 0.4$ & $6.6 \pm 0.5$ & $7.5 \pm 0.5$ & $6.7 \pm 0.5$ \\
Normal ambient & $7.2 \pm 0.8$ & $6.5 \pm 0.3$ & $7.7 \pm 0.5$ & $6.2 \pm 0.5$ \\
Hot, humid & $7.0 \pm 0.4$ & $7.3 \pm 0.4$ & $6.7 \pm 0.5$ & $6.7 \pm 0.5$ \\
\hline
\end{tabular}

a Definitions as in Table 2

b Percentage increases for these values compared with baseline are significantly different $(p<$ 0.05 ) than the percentage increases for the other times of measurements at the same conditions

Table 4. Measurements of $\mathrm{FEV}_{\mathrm{l}} / \mathrm{FVC}$ for asthmatic and normal subjects during different exposure conditions

\begin{tabular}{lllll}
\hline $\begin{array}{l}\text { Exposure } \\
\text { condition }\end{array}$ & \multicolumn{4}{c}{ Time of measurement } \\
\cline { 2 - 5 } & Baseline & $2 \mathrm{hr}$ & $\begin{array}{l}\text { 10 min after } \\
\text { exercise at } \\
4 \mathrm{hr}\end{array}$ & $6 \mathrm{hr}$ \\
& & & & \\
\hline Asthmatic subjects & & & & \\
Cold, dry & $71.0 \pm 4.0$ & $69.9 \pm 5.0$ & $64.1 \pm 5.5$ & $71.9 \pm 3.6$ \\
Cold, humid & $72.0 \pm 4.3$ & $69.0 \pm 4.6$ & $62.4 \pm 5.8$ & $69.1 \pm 5.8$ \\
Hot, dry & $72.2 \pm 4.2$ & $74.2 \pm 4.4$ & $66.4 \pm 6.1$ & $74.9 \pm 4.9$ \\
Normal ambient & $74.5 \pm 4.4$ & $74.1 \pm 4.6$ & $70.0 \pm 6.0$ & $76.7 \pm 5.1$ \\
Hot, humid & $73.5 \pm 3.2$ & $75.2 \pm 4.0$ & $74.4 \pm 5.1$ & $74.6 \pm 4.4$ \\
Normal subjects & & & & \\
Cold, dry & $78.9 \pm 1.2$ & $78.1 \pm 0.8$ & $78.9 \pm 1.4$ & $77.5 \pm 1.1$ \\
Cold, humid & $80.2 \pm 1.6$ & $81.0 \pm 1.2$ & $80.8 \pm 1.9$ & $79.4 \pm 1.3$ \\
Hot, dry & $81.4 \pm 2.1$ & $81.5 \pm 1.9$ & $80.6 \pm 2.1$ & $80.1 \pm 1.7$ \\
Normal ambient & $81.8 \pm 2.0$ & $80.9 \pm 1.6$ & $81.1 \pm 2.0$ & $79.8 \pm 1.4$ \\
Hot, humid & $80.5 \pm 1.7$ & $81.4 \pm 1.7$ & $83.4 \pm 2.1$ & $81.2 \pm 1.6$ \\
\hline
\end{tabular}

a Definitions as in Table 2 
Table 5. Work performance of asthmatic and normal subjects during different exposure conditions (mean \pm SEM)

\begin{tabular}{lllll}
\hline $\begin{array}{l}\text { Exposure } \\
\text { condition }\end{array}$ & $\begin{array}{l}\mathrm{V}_{\mathrm{E}} \\
(\mathrm{L} / \mathrm{min})\end{array}$ & $\begin{array}{l}\text { Workload } \\
(\text { watts })\end{array}$ & HR (bpm) & $\begin{array}{l}\mathrm{VO}_{2} \\
(\mathrm{~L} / \mathrm{min})\end{array}$ \\
\hline $\begin{array}{l}\text { Asthmatic subjects } \\
\text { Cold, dry }\end{array}$ & $65.9 \pm 4.5^{+}$ & $145.8 \pm 9.7$ & $155.4 \pm 4.2$ & $2.39 \pm 0.15$ \\
Cold, humid & $68.9 \pm 5.6$ & $147.7 \pm 15.2$ & $153.9 \pm 7.1$ & $2.50 \pm 0.19$ \\
Hot, dry & $69.6 \pm 5.3$ & $120.9 \pm 7.7$ & $169.0 \pm 4.6$ & $2.65 \pm 0.16$ \\
Normal ambient & $69.9 \pm 4.8$ & $137.8 \pm 12.2$ & $158.1 \pm 4.5$ & $2.69 \pm 0.15$ \\
Hot, humid & $72.0 \pm 4.7$ & $130.2 \pm 11.3$ & $170.0 \pm 6.6$ & $2.72 \pm 0.16$ \\
Normal subjects & & & & \\
Cold, dry & $90.4 \pm 7.5$ & $150.6 \pm 19.6$ & $158.5 \pm 6.7$ & $2.83 \pm 0.24$ \\
Cold, humid & $94.6 \pm 7.2$ & $156.8 \pm 16.3$ & $161.5 \pm 5.6$ & $3.04 \pm 0.24$ \\
Hot, dry & $88.5 \pm 7.5$ & $150.5 \pm 16.2$ & $168.6 \pm 5.0$ & $3.06 \pm 0.27$ \\
Normal ambient & $96.9 \pm 8.8$ & $146.2 \pm 15.7$ & $163.6 \pm 4.6$ & $3.21 \pm 0.26$ \\
Hot, humid & $95.5 \pm 8.3$ & $140.4 \pm 14.7$ & $172.4 \pm 4.5$ & $3.18 \pm 0.28$ \\
\hline
\end{tabular}

a Definitions as in Table 2

same for each subject on the different days. By this technique of matching minute ventilations, we hoped to make each exposure and exercise period equivalent for the different exposure conditions. The results of the exercise periods for the asthmatic and normal subjects for all 5 exposure conditions are shown in Table 5 . The values shown were obtained by averaging the minute by minute values for the last $8 \mathrm{~min}$ of the $10 \mathrm{~min}$ exercise period for each subject and then averaging the results for all 8 subjects of each group. Although there was not a significant difference among the minute ventilations for the different exposure days within each group, the external workloads performed on the days with the higher temperature $\left(37^{\circ} \mathrm{C}\right)$ tended to be less than the workloads on the days with the lower temperature $\left(10^{\circ} \mathrm{C}\right)$, whereas the oxygen consumptions were greater on the days with the higher temperature. For the subjects with asthma, the workload in watts performed per $\mathrm{L} / \mathrm{min}$ of oxygen consumed was significantly greater during the cold and dry conditions $(61.4 \pm 3.1$ watts $/ \mathrm{L} /$ $\mathrm{min})$ than during the hot and humid conditions $(47.4 \pm 1.9 \mathrm{watts} / \mathrm{L} / \mathrm{min})(\mathrm{p}<$ 0.05).

\section{Discussion}

We have shown that when normal male subjects and male subjects with asthma are exposed to carefully controlled extremes of humidity and temperature in an environmental chamber, the resulting pulmonary responses and work performance characteristics related to exercise can be significantly affected. The decrease in lung function in asthmatic subjects brought on by the exercise under low-moisture conditions could well have been anticipated from previous work. 
What was not anticipated was the improvement in lung function (increase in $\mathrm{FEV}_{1}$ ) that occurred when normal subjects exercised under hot, humid conditions. This suggests that the hot, humid conditions associated with many air pollution episodes by themselves should not be responsible for any resulting decreases in lung function. Accordingly, the associations found between ambient ozone and daily changes in ventilatory function $[9,13]$, cannot be attributed to the heat and humidity stress often associated with high ozone concentrations. However, it is still possible that there might be some interaction between heat and humidity stress and the adverse health effects of certain air pollutants that will require additional evaluation.

Normal subjects and subjects with asthma when at rest in a chamber exhibited no changes in pulmonary function tests over a $6 \mathrm{hr}$ period despite differences in temperature and humidity from $10^{\circ} \mathrm{C}$ and $10 \%$ relative humidity to $37^{\circ} \mathrm{C}$ and $60 \%$ relative humidity. However, the pulmonary responses after a period of exercise during the exposure were considerably different and seemed to be best correlated with the water content of the chamber air: the lower the water content, the greater the bronchoconstriction that occurred after exercise in the asthmatic subjects and the less the bronchodilation that occurred in the normal subjects. For comparison, the $20-21 \%$ decrease in $\mathrm{FEV}_{1}$ for subjects with asthma after exercise in the conditions of low water content is comparable to the 24\% decrease in $\mathrm{FEV}_{1}$ for subjects with asthma after exercising in an 0.4 ppm ozone environment that we reported previously [10]. It has been shown previously that subjects with asthma will experience bronchoconstriction when exercising or hyperventilating in environmental conditions of water content less than $44 \mathrm{mg} / \mathrm{L}$ (the conditions of saturated air at body temperature or $37^{\circ} \mathrm{C}$ ) $[1-3$, 8]. It has also been shown that normal subjects and subjects with asthma may have a certain degree of bronchodilation as a result of exercise [6, 7]. Thus, the pulmonary response to exercise for subjects with asthma will be a result of the balance beween the bronchodilation and the bronchoconstriction. Of interest, not only did we find a highly significant correlation between the water content of the exposure conditions and the bronchoconstriction for the subjects with asthma but we also found a highly significant correlation between the bronchodilation for the normal subjects and the water content of the chamber. It is possible that even in normal subjects minimal bronchoconstriction occurs as the result of exercise. This bronchoconstriction will usually be balanced by the bronchodilation that also occurs. Thus, when normal subjects exercise in conditions similar to body temperature with completely saturated air, this minimal bronchoconstriction is eliminated and the bronchodilation becomes more evident.

In contrast to the pulmonary function results, the work performance characteristics of the subjects were more directly related to the temperature than the water content: the higher the temperature, the lower the external work performed for an equivalent amount of oxygen consumed (a decrease of approximately $23 \%$ for the subjects with asthma). It has been shown previously that exercising at temperatures above normal ambient conditions can adversely affect the hemodynamic and performance characteristics of exercising subjects $[4,11,12]$. In response to exercise, there are increases in cardiac output to 
supply oxygen and other nutrients to the contracting muscles and to increase blood flow to the skin for increased heat transfer to the environment. At the same time, there is a systemic sympathetic vasoconstriction of several vascular beds (including visceral systems for the diversion of blood to the muscles and skin). There are believed to be opposing phenomena competing for control of the exercising muscles' vasculature. These are the local metabolic needs leading to vasodilation and the systemic sympathetic outflow leading to vasoconstriction. The added stress of increased temperature results in well-described changes in metabolism of the exercising muscles and hemodynamic changes in the general circulation $[4,11,12]$. Although these changes have been documented for normal subjects, little information has been reported for subjects with asthma. For normal subjects, Nadel et al. [12] have shown that when individuals exercise at a workload equivalent to approximately $70 \%$ of their maximal attainable workload $\left(\mathrm{VO}_{2}\right.$ of approximately $\left.2.8 \mathrm{~L} / \mathrm{min}\right)$, there were differences in heart rate and stroke volume of the heart at different external temperatures. At $20^{\circ} \mathrm{C}$, after $12 \mathrm{~min}$, the mean heart rate was $155 \mathrm{bpm}$ and the mean stroke volume was $122 \mathrm{ml}$. However, at $36^{\circ} \mathrm{C}$, after $10.4 \mathrm{~min}$, the mean heart rate was $172 \mathrm{bpm}$ and the mean stroke volume was $105 \mathrm{ml}$. They found that the resulting cardiac output was not different for the 2 temperatures but that the increased cardiac output was achieved by different mechanisms. MacDougall et al. [11] also found that the heart rate was significantly increased at the same workload under conditions of increased heat stress. At $36-37^{\circ} \mathrm{C}$ and again at a workload equivalent to $70 \%$ of the maximal oxygen consumption, they found that the heart rate after 20 min was 181 compared with a heart rate of 170 for external temperatures of $18^{\circ} \mathrm{C}$. However, they found, in contrast to Nadel and colleagues, that the stroke volume of the heart was also increased by $25 \%$ for the higher temperature, resulting in a significantly increased cardiac output for the higher temperature. They also noted that as an indicator of work performance, the work tolerance time was significantly reduced for the subjects when exercising at the higher temperature: work tolerance time at $36-37^{\circ} \mathrm{C}$ was $48.25 \mathrm{~min}$, whereas it was $90.75 \mathrm{~min}$ at $18^{\circ} \mathrm{C}$. Fink et al. [4] have also demonstrated the increased metabolic stress as a result of heat stress added to exercise. They have demonstrated that at $41^{\circ} \mathrm{C}$ and $15 \%$ relative humidity, subjects exercising at 70-85\% of their maximal oxygen consumption had heart rates of 160 after $15 \mathrm{~min}$ and twice the blood lactate concentrations compared to exercising at the same workload but at $9^{\circ} \mathrm{C}$ and $55 \%$ relative humidity. The heart rate after $15 \mathrm{~min}$ at the lower temperature was 132 . We have found that while we try to keep the minute ventilation constant for the exercise periods at the different exposure conditions, at the higher temperature $\left(37^{\circ} \mathrm{C}\right)$ the heart rate is higher and there is a reduction in the workload achieved for an equivalent amount of oxygen consumed for both the subjects with asthma and the normal subjects. Thus our results are in agreement with the previous findings, but we were able to extend the findings to include subjects with asthma.

In summary, we have found that altering the conditions of temperature and humidity in an environmental chamber can have profound but different effects on both the pulmonary responses and work performance characteristics of 
normal subjects and subjects with asthma. It is essential that in designing controlled exposure studies to air pollutants or evaluating the results of field studies, the conditions of temperature and humidity be known and considered, and their potential as confounding factors be considered when evaluating the pulmonary and exercise performance responses of human subjects.

\section{References}

1. Chen WY, Horton DJ (1977) Heat and water loss from the airways and exercise-induced asthma. Respiration 34:305-313

2. Deal EC Jr, McFadden ER Jr, Ingram RH Jr, Strauss RH, Jaeger JJ (1979) Role of respiratory heat exchange in production of exercise-induced asthma. J Appl Physiol 46:467-475

3. Eschenbacher WL, Sheppard D (1985) Respiratory heat loss is not the sole stimulus for bronchoconstriction induced by isocapnic hyperpnea with dry air. Am Rev Respir Dis 131:894-901

4. Fink WJ, Costill DL, VanHandel PJ (1975) Leg muscle metabolism during exercise in the heat and cold. Europ J Appl Physiol Occup Physiol 34:183-190

5. Friedlander SK, Altshuler B, Bayes KD, Eschenroeder AQ, Hackney JD, Heck WW, McCarroll JR, McNesby JR, Miller PR, Mueller PK, Murphy SD (1977) Ozone and other photochemical oxidants. National Academy of Sciences, Washington, DC

6. Gelb AF, Tashkin DP, Epstein JD, Gong H, Zamel N (1985) Exercise-induced bronchodilation in asthma. Chest 87:196-201

7. Haas F, Pasierski S, Levine N, Bishop M, Axen K, Pineda H, Haas A (1987) Effect of aerobic training on forced expiratory airflow in exercising asthmatic humans. J Appl Physiol 63:1230-1235

8. Hahn A, Anderson SA, Morton AR, Black JL, Fitch KD (1984) A reinterpretation of the effect of temperature and water content of the inspired air in exercise-induced asthma. Am Rev Respir Dis 130:575-579

9. Higgins ITT, D'Arcy JB, Gibbons DI, Avol EL, Gross KB (1990) Effect of exposures to ambient ozone and ventilatory lung function in children. Am Rev Respir Dis 141:1136-1146

10. Kreit JW, Gross KB, Moore TB, Lorenzen TJ, D'Arcy J, Eschenbacher WL (1989) Ozoneinduced changes in pulmonary function and bronchial responsiveness in asthmatics. J Appl Physiol 66:217-222

11. MacDougall JD, Reddan WG, Layton CR, Dempsey JA (1974) Effects of metabolic hyperthermia on performance during heavy prolonged exercise. J Appl Physiol 36:538-544

12. Nadel ER, Cafarelli E, Roberts MF, Wenger CB (1979) Circulatory regulation during exercise in different ambient temperatures. J Appl Physiol 46:430-437

13. Spektor DM, Lippmann M, Lioy PJ, Thurston K, Citak DJ, Bock N, Speizer FE, Hayes C (1988) Effects of ambient ozone on respiratory function in active normal children. Am Rev Respir Dis 137:313-320

Accepted for publication: 21 August 1991 